\title{
Country Land Building Intensity Contrast of Binzhou City Based on RS and GIS
}

\author{
Jianlin Wang ${ }^{1,2, *}$, Yinsheng Yang ${ }^{1}$ and Lei Wang ${ }^{3}$ \\ ${ }^{1}$ College of Biological and Agricultural Engineering, Jilin University, Changchun 130022, China; ${ }^{2}$ Department of \\ Computer Science, Binzhou University, Binzhou 256600, China; ${ }^{3}$ Department of Mathematics, Binzhou University, \\ Binzhou 256600, China
}

\begin{abstract}
This paper selects TM remote sensing image of May, 2009a, land use map and land use changing data of 2008a as data materials, combined with some partly field data, it studied the land building intensity of seven counties of Binzhou city, some conceptions and related measure methods were proposed. The results showed that the land building intensity was in middle and low level contrast in national scale, and belong to low level contrast in global scale. Finally, some countermeasures was put forward to enhance land building intensity of Binzhou city.
\end{abstract}

Keywords: Binzhou city, geographic information systems, land building intensity, remote sensing.

\section{INTRODUCTION}

Land is the most basic and important resource for human survival and development. Beyond doubt, it's also the most basic and important resource in modern economic development. Land development intensity is related closely to human life and economic development, and the level of land development intensity has a dynamic effect on economic development. The inconsistency is apparently because data and metho-dological approaches vary across analyses, and the institu-tional framework differs across countries involved. To illustrate the complexity involved, we will focus on one par-ticular country, namely Finland. The detailed micro data offered by the Finnish longitudinal population registers provide opportunities for sufficiently detailed analysis. The aim with this paper is to give more in-depth evidence.

Land development intensity includes several leading indicators, which are plot ratio, building density, building height and greening rate. Under general circumstances, the higher land development intensity is, the higher the economic benefit of land use is; on the contrary, if land development intensity is relatively low or insufficient, that is, if land isn't fully used, or uncertain land use leads to an decrease in development intensity, land's use value will be weakened. The loose construction and massive investments in infrastructure arising in the current urban development will cause a huge waste of land resources. China, especially the developed regions, must resolutely guard against this phenomenon. We should learn lessons in time and make regional planning to rationally guide urban development layout [1].

*Address correspondence to this author at the College of Biological and Agricultural Engineering, Jilin University, Changchun 130022, China; Tel: 18554300068; E-mail: bzxywjl@163.com
Therefore, we should devote ourselves to rationally developing, utilizing and protecting the limited land resources, and this is also a precondition for regional economic development and sustainable development. This paper discussed and researched the county-level development intensity of Binzhou City, aimed at providing a management and decision basis for Binzhou City's urban development.

\subsection{Research Background}

Binzhou is the interior of Yellow River Delta, located in the downstream of the Yellow River and North Shandong Plain, the northern part of Shandong Province, and on the southwestern coast of Bohai Bay, bordered by Zibo City in the south, Dongying City in the east, Jinan City in the southwest, and Dezhou City in the west. Binzhou City now consists of six counties and a district, including Bincheng District, Huimin County, Yangxin County, Wuli County, Zhanhua County, Boxing County and Zouping County. Its administrative map is shown below (Fig. 1).

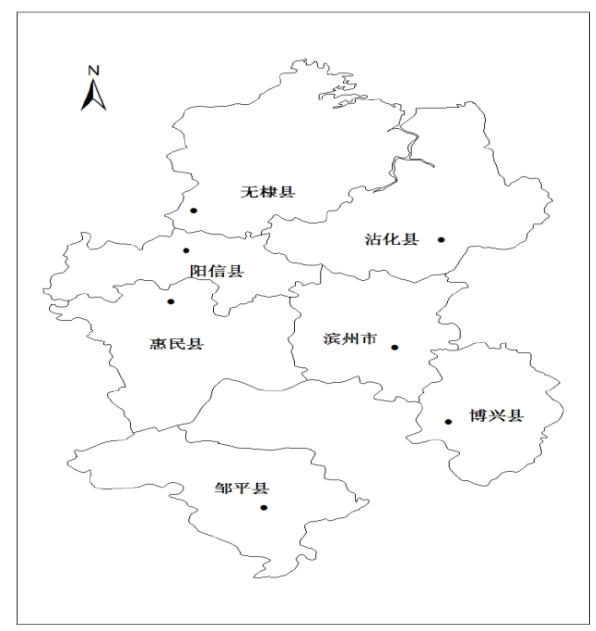

Fig. (1). The administrative division of the investigated area. 
Land is an important fundamental resource in modern urban construction and economic development, and the most important and basic resource for human survival and development. It's non-renewable and irreplaceable. Particularly, land development intensity is related closely to economic development, so reasonable land development intensity will produce a positive and profound impact on the enhancement of urban promoting function, the construction of a well-off society in an all-around way, and the sound and fast development of economic society.

It can be seen from the utilization status of land in Binzhou City's urban construction that the level of economical and intensive land use is being gradually increased. Particularly in the recent years, a significant change has taken place to land utilization type and concept, but there is still something less than satisfactory in function division, investment intensity and land utilization rate. The efficiency of land use is relatively low. At present, the municipal government makes an assessment on its achievements mainly according to the evaluation system in which regional GDP serves as the core. This evaluation system doesn't really include economical and intensive land use, so it's inevitable that land is used extensively, while economical and intensive land use is hard to carry out effectively.

Therefore, rational protection of the limited land resources and moderate development and utilization of the existing land resources should serve as a constant principle in urban construction. This is likewise a precondition for the achievement of regional sustainable development, more related to the global, strategic problem on the sustainable development of national economy and society. In recent years, with the rapid development of Binzhou City's urbanization and industrialization, the major project and municipal infrastructure construction has raised increasing demand on land, and this has brought a new issue to Binzhou City's land exploration and utilization. Comprehensive utilization of RS (remote sensing) and GIS (geographic information system) technologies for research on land development intensity in this paper can help grasp the changing status of land use comprehensively, timely and accurately, so as to save lots of human resources, material resources, financial resources and time, to provide a management and decision basis for Binzhou City to make a quantitative evaluation on land development intensity, and develop and use land scientifically and rationally [2].

\subsection{Research Significance}

In the process of China's current urban construction, renewal and reconstruction, owing to the constraints of economic factors, most enterprises and public institutions hope to develop and utilize the existing construction land highinsensitively. For this reason, land's economic effectiveness has been improved. But in the meantime, due to the excessive land development intensity, urban infrastructure has been overwhelmed, and other resource elements, as well as municipal facilities, have been occupied and even destroyed. For instance, such communal ancillary facilities in the urban area as greenbelts, museums and parking lots have been occupied, some historical cultural relics or their surroundings have been damaged to varying degree. These development modes with a plot ratio and high density in urban area not only easily cause a decrease in the overall efficiency, but also add severe burden to municipal infrastructure and trigger serious environmental problems. So we should pay attention to the rational layout of urban spatial structure. Urban spatial structure is reflected not only in the urban spatial organization in a country or region, that is, in the urban hierarchical system, but also in the urban interior structure. It's the spatial carrier and realization form of urban function. Urban spatial structure also develops dynamically with the change of urban elements and external environments [3].

To improve the economic effectiveness of land use, it's feasible to first improve land development density and carry out land integration, and this practice can help avoid the immoderate development of land resources. However, intensive and high-strength development of land sources doesn't mean infinite reduction in the use scale of urban land resources, but the setting of a reasonable development intensity goal. When setting a goal for national territorial development intensity, we should carry out scientific development perspective thoroughly, enhance development coordination, handle the conflict between the limited national land space and increasing demand seriously, and make national territorial development intensity harmonious with ecological environment. Meanwhile, we should carry out differential regional land use policies based on the land use policy of Binzhou determined by the country, to strengthen regulation and control over use utilization, and implement the strictest economical and intensive land use system [4].

Under normal circumstances, when land development intensity increases, the economic effectiveness of land use will increase accordingly; on the contrary, when land development intensity decreases, that is, when land isn't developed or used sufficiently, or when land development intensity is weakened by misuse of land, the use value of land resources will be lowered. Land development intensity is affected by such factors as regional spatial structure, economy, society and policy, and shows different results in regional space [5].

There is a difference among different regions in natural resource endowment, socioeconomic condition and development phase, and there is also a difference in regional land development intensity, so different regional land development intensities have different upper limit values. An appropriate upper limit for regional land development intensity relies on a region's maximum land supporting capability. Unreasonable land development or ultra-intense development will lead to a structural disorder and functional deterioration in the region's internal land system, and finally will certainly hinder the sustainable development of this region's economy and society. This paper aims to calculate the county-level land development intensity of Binzhou City, and make a comparative study on spatial domain and time domain, to learn about the status quo of Binzhou City's land development, and put forward specific opinions and suggestions for land development, to coordinate regional development and realize the sustainable utilization of land resources.

\section{DOMESTIC AND OVERSEAS RESEARCH PRO- GRESS}

To discuss the level of land development intensity, research the appropriateness of land development to economic 
development, and use urban land rationally and efficiently to achieve sustainable development, lots of scholars have done research into land development intensity from different perspectives. Yao Deming, Chen Yufu and Zhang Fugang made a quantitative evaluation on the land development intensity of Hainan Province and its 18 cities and counties by the use of reference system comparison method [6]; Zou Bin, Yang Yanqiong and Xue Yadong, with the satellite image of Pearl River Delta in 2003 and 2007 as a data source, on the basis of some field investigation data, used land utilization changing model and method to analyze the rangeability, dynamic degree and change scope of the land in Pearl River Delta [7]; Zhou Bingzhong, Bao Haosheng and Peng Buzhuo researched the issue about high-strength exploitation of land resources and the land development in Yangtze River Delta, pointed out the connotation of land development intensity and put forward a corresponding measurement method based on theoretical explanation and quantitative analysis evaluation, and gave a scientific definition to "high-strength development of land resources" [8]; Zhou Suhong et al. discussed the impact of land development intensity on transportation development strategy, traffic and urban operating efficiency, transport infrastructure and traffic demand [9]. Based on the existing statistical information of the UN, World Bank, and China as well as its provinces and cities in 1985, 1990 and 1995 , as well as on other relevant statistical, observational and survey data, and the previous related scientific research achievements, the world development report analyzed, screened and established a database that could reflect different sizes of spatial units and the development \& utilization intensity of land resources in different periods $[10,11]$.

It can be seen from these scholars' researches that there are many restraining factors for land development intensity, and there hasn't yet been a unified quantitative evaluation on its research. Among those scholars, some made a qualitative assessment, some made an assessment based on the method they made, and some carried out a regional comparative study. The scholars' research result shows that land development intensity and regional economy influence and restrict each other: as land development and utilization intensity increases, land output level also increases, that is, there is a positive correlation between the two. In addition, if economic and social condition varies, the same development and utilization intensity will make different contributions to different region's output level and to a region's output level at different times. This is exactly decided by the regional difference, versatility and socioeconomic status of land resource status. Fuzzy comprehensive evaluation is a very effective multi-factor decision method used to comprehensively evaluate something influenced by multiple factors, and a highly integrated evaluation method used to turn qualitative evaluation into quantitative evaluation in accordance with the membership grade theory in fuzzy mathematics. It can help control human interference factors efficiently.

\section{THE ESTABLISHMENT OF FUZZY COMPRE- HENSIVE MODLE}

(1) Set up a fuzzy comprehensive evaluation set. Let the influencing factor for the evaluation object be:

$$
\varphi=\arccos \frac{\left(z_{n 13}-z_{n 1}\right)}{L_{n}},
$$

and evaluation set:

$$
V=\left\{v_{1}, v_{2}, \cdots, v_{n}\right\} ;
$$

(2) Determine the membership degree of the various related factors of the evaluated. First of all, make a singlefactor evaluation on the single factor $u_{i}(i=1,2, \cdots, m)$ in set $U$, to determine the degree $R_{i j}$ of this object's membership to order of evaluation $v_{j}(j=1,2, \cdots, n)$, then get the singlefactor evaluation set $r_{i}=\left(r_{i 1}, r_{i 2}, \cdots, r_{i m}\right)$ of the $i$ th factor $u_{i}$, which is a fuzzy subset in evaluation set $V$. Then, the evolution sets of $m$ factors form an overall evaluation matrix $R$, which reflects certain correlativity between set $U$ and set $V$ :

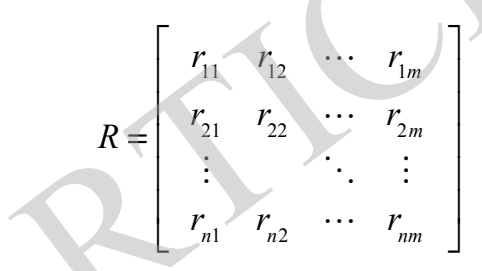

where, $R_{i j}$ represents the degree of the membership of factor $u$ to choice grade $v_{j}$. It lays a foundation for fuzzy comprehensive evaluation.

(3) Determine the weight of each evaluation factor to the evaluation object. For the evaluated, since entirely different conclusions can be reached from different factors, and that in many factors $u_{i}(i=1,2, \cdots, m)$, the influence on the general evaluation varies, and there are fuzzy preferential factors, the perspective of the evaluation can be regarded as fuzzy subset $A$ in factor domain $U$, denoted as: $A\left(a_{1}, a_{2}, \cdots, a_{m}\right)$; in the equation, $a_{i}\left(0 \leq a_{i} \leq 1\right)$ means the degree of the membership of $u_{i}$ to $A$, and it is used to measure the effect degree of single factor $u_{i}$ in the overall evaluation. It's known as factor $u_{i}$ 's importance degree coefficient, or weight.

(4) Comprehensive evaluation. After fuzzy matrix R and fuzzy vector A are determined, fuzzy transformation can be carried out for comprehensive evaluation: $B=A \circ R=\left(b_{1}, b_{2}, \cdots, b_{n}\right)$. The evaluation indexes of land development intensity are hierarchical, and there are many kinds of indexes, which need to be evaluated comprehensively at multiple levels. We can regard the factors at the lower levels as sub-problems, and first make a comprehensive evaluation on the sub-problems respectively. Then, we can make a comprehensive evaluation on the totality. That is, we can first synthesize the factors at the lower levels, and then synthesize the factors at the upper level.

\section{AN EVALUATION ON THE COUNTY-LEVEL LAND DEVELOPMENT INTENSITY OF BINZHOU CITY}

In this evaluation, Binzhou City's present land-use map and statistical data on land use change in 2008 are taken as a 
data source, and some field investigation data is taken as an evaluation basis.

\subsection{The Selection and Quantization of Evaluation Index System}

\subsubsection{The Selection of Index System}

First-class evaluation index system falls into * aspects, including use condition, input intensity, use degree and use efficiency. The selection of the second-class evaluation indexes contained is shown below:

1) Use condition, including: i) agricultural acreage per capita; ii) construction land area per capita; iii) population density; iv) GDP per capita.

2) Output intensity, including: i) fixed-asset investment in arable land; ii) chemical fertilizer investment in arable land; iii) total powr of farming machine

3) Use degree, including: i) Land reclamation rate; ii) building density of infrastructure; iii) construction land's ratio to land area; iv) farmland reclamation rate

4) Use efficiency, including: i) grain yield from farmland; ii) agriculture production value; iii) the secondary and tertiary industries' output value.

\subsubsection{The Quantization of Index System}

According to experts' experience-based judgment and the method of mathematical quantification, this paper uses Delphi method and analytic hierarchy process, which can correct each other, to determine a weight for each evaluation index. Finally, index weight is shown in Tab.1 below.

\subsubsection{Grading Classification and Standard Setting for Evaluation Indexes}

According to the requirement of general fuzzy comprehensive evaluation method and others' studies, this paper divides the indexes into four grades, as shown below:

$\mathrm{B}=$ (superior, good, so-so, and bad)

Based on the expert scoring and the project area's practical situation, the paper determines the membership degree of second-class index grade, with the result shown in Table 1.

\subsection{Calculation and Analysis}

\subsubsection{The Calculation of Evaluation Grade and Character-} istic Value

For the fuzzy comprehensive evaluation on land development intensity, $\mathrm{M}(\cdot, \oplus)$ operator is selected for multilevel fuzzy comprehensive evaluation. To better evaluate the implementation of first-class indexes, we introduce characteristic value for a comparison. " $1,2,3$ and 4" are assigned to the characteristic value, which correspond to "superior, good, so-so and bad", the grade of single index, respectively. Calculate the evaluation indexes' evaluation grade and characteristic value according to fuzzy comprehensive evaluation model, weight and membership degree.

The evaluation result of use condition index:
$B=A \bullet R=\left[\begin{array}{ll}0.6 & 0.4\end{array}\right] \bullet\left[\begin{array}{cccc}0.8 & 0.2 & 0 & 0 \\ 0.6 & 0.2 & 0.1 & 0.1\end{array}\right]$

$=\left[\begin{array}{llll}0.72 & 0.20 & 0.04 & 0.04\end{array}\right]$

Characteristic value $=(1,2,3,4) \times(0.72,0.20,0.04$, $0.04)$

$=1.4$

The evaluation result of output intensity index:

$$
\begin{aligned}
& B=A \bullet R=\left[\begin{array}{lllll}
0.2 & 0.2 & 0.2 & 0.25 & 0.15
\end{array}\right] \bullet\left[\begin{array}{cccc}
0.1 & 0.8 & 0.1 & 0 \\
0.9 & 0.1 & 0 & 0 \\
0.2 & 0.8 & 0 & 0 \\
0.1 & 0.7 & 0.1 & 0.1 \\
0.1 & 0.7 & 0.2 & 0
\end{array}\right] \\
& =\left[\begin{array}{llll}
0.28 & 0.62 & 0.075 & 0.025
\end{array}\right] \\
& \text { Characteristic value }=(1,2,3,4) \times(0.28,0.62,0.075, \\
& 0.025)=1.845
\end{aligned}
$$

The evaluation result of use intensity index:

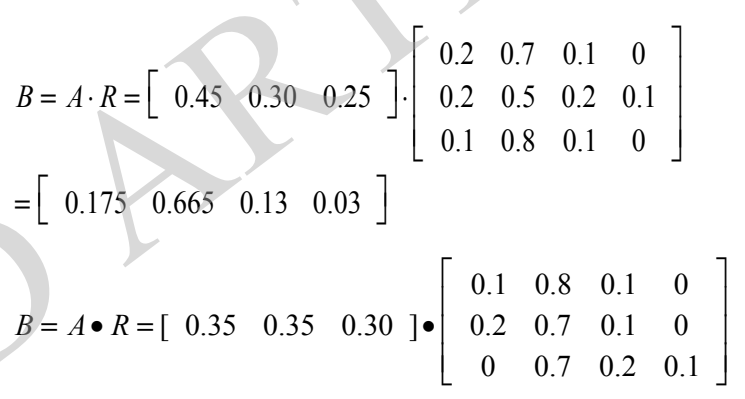

Characteristic value $=(1,2,3,4) \times(0.105,0.735,0.13$, $0.13)=2.085$

The evaluation result of use efficiency index:

$$
\begin{aligned}
& B=A \bullet R=\left[\begin{array}{llll}
0.25 & 0.35 & 0.25 & 0.15
\end{array}\right] \bullet\left[\begin{array}{cccc}
0.72 & 0.20 & 0.04 & 0.04 \\
0.28 & 0.62 & 0.075 & 0.025 \\
0.105 & 0.735 & 0.13 & 0.03 \\
0.175 & 0.665 & 0.13 & 0.03
\end{array}\right] \\
& =\left[\begin{array}{llll}
0.331 & 0.551 & 0.088 & 0.031
\end{array}\right]
\end{aligned}
$$

The evaluation result of $(1,2,3,4) \times(0.175,0.665,0.13$, $0.03)=2.015$

The first-class index weights in Tab.1 form weight matrix $A$, and the evaluation results of the second-class indexes form comprehensive evaluation matrix R. Evaluate grade B after calculating the counties' land development intensity.

Characteristic value $=(1,2,3,4) \times(0.331,0.551,0.088$, $0.031)=1.819$

\subsubsection{Analysis Evaluation}

It can be seen from the comprehensive evaluation result that "superior" accounts for $33.1 \%$, "good" accounts for $55.1 \%$, "so-so" accounts for $8.8 \%$, and "bad" accounts for $3.1 \%$. According to maximum membership principle, the quality of this city's land use intensity is "good", most goals have been achieved, and the expected influence has been realized. 
Table 1. The grade standard and membership degree of the evaluation indexes of binzhou city's county-level land development intensity.

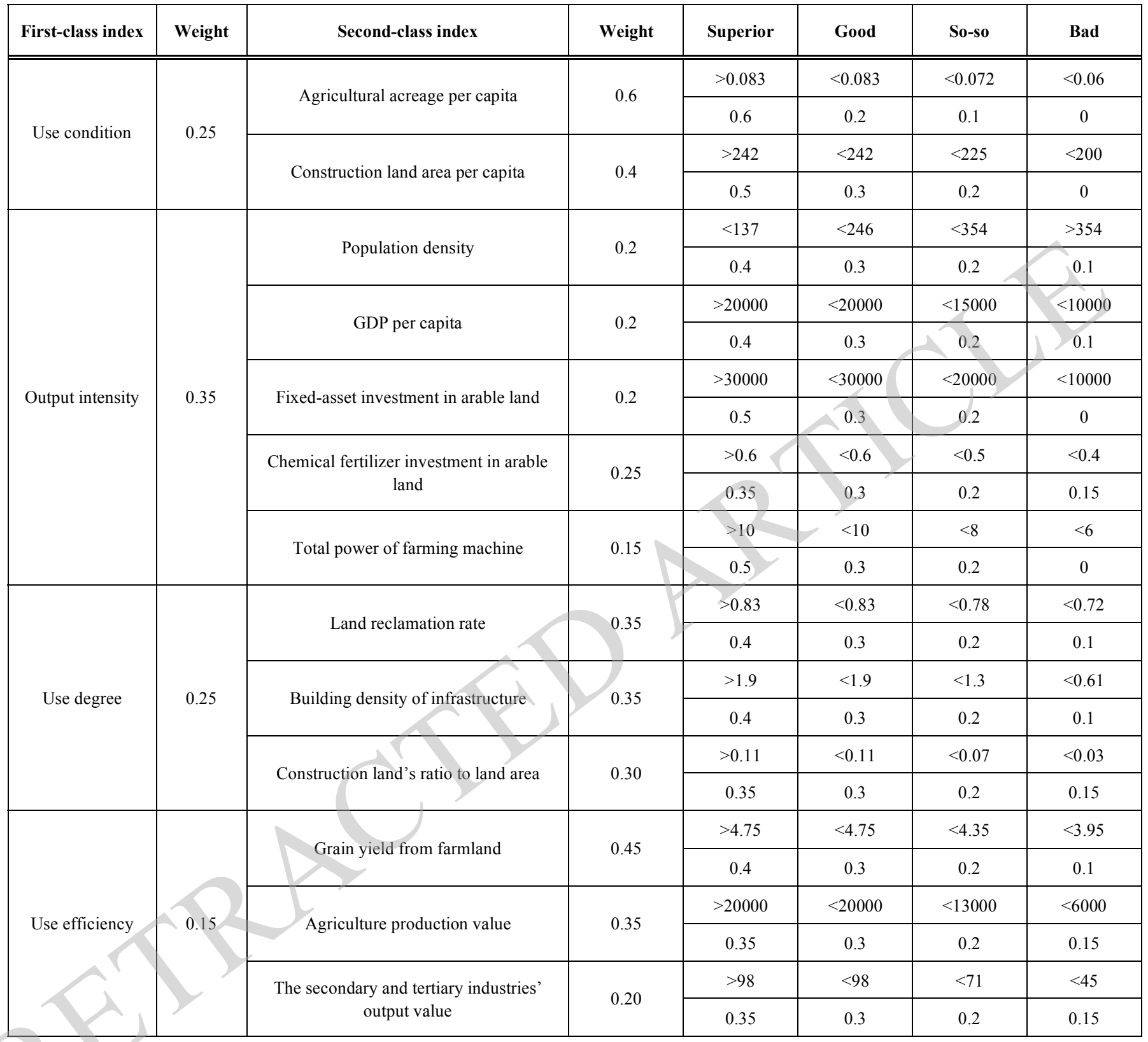

The bigger characteristic value is, the lower this index's success degree is, while the smaller characteristic value is, the higher the success degree is. The first-class indexes' characteristic value suggests that $1.4<1.845<2.015$ $<2.085$, so we can get to know that Binzhou City's land development intensity and use efficiency are high.

\section{CONCLUSION AND SUGGESTION}

(1) On the whole, Binzhou City's land development intensity is comparatively rational, quality is high, land use condition is favorable, and use degree is high. In the future development, it should give full play to its resource superiority and regional advantage, and increase investment in the land that has been used, to improve the land use efficiency.
(2) There is still a large rising space for the development and utilization intensity of Binzhou City's land resources. Especially, there is a larger rising space for the output intensity and use efficiency. Therefore, in future land utilization, Binzhou City shouldn't develop the unused land on a large scale, but should improve the land development intensity by strengthening the output intensity, tapping the land potential, and using the land intensively.

\section{CONFLICT OF INTEREST}

The authors confirm that this article content has no conflict of interest. 


\section{ACKNOWLEDGEMENTS}

Declared none.

\section{REFERENCES}

[1] C. Gu, and Y. Sun , The new development tendency of Chinese big cities'-suburbanization”, Planner, vol. 14, no. 2, pp. 102-104, 1998.

[2] Urban Land Classification and Construction Land Planning (GBJ137-90). Beijing: Ministry of Construction, pp. 3-10, 1990.

[3] Y. Zhang, and D. Du, "Functional transfer of central shanghai and urban spatial structure optimization", Urban Development Studies, vol. 8, no. 6, pp. 44-49, 2001.

[4] K. Liu, "An discussion on guizhou province's national territorial development intensity", Traffic and Municipal Construction, pp. 153-155, 2011.

[5] L. Ding and W. Qu, "An discussion on land development intensity from the perspective of self-organization — a case study of pingli- ang city's regulatory detailed planning", Planning and Design, pp. 12-17, 23, 2011

[6] D. Yao, Y. Chen, and F. Zhang, "An evaluation research on hainan province's land development intensity", Journal of Hebei Agricultural Sciences, vol. 12, no. 1, pp. 86-87, 2008.

[7] B. Zou, Y. Yang, and Y. Xue, "An dynamic analysis on rs and gisbased land use in pearl river delta", Forest Resources Management, vol. 6, pp. 110-116, 2011.

[8] B. Zhou, H. Bao, and B. Peng, "An evaluation on the land development intensity in pearl river delta", Geographical Science, vol. 20, no. 3, pp. 218-223, 2000.

[9] S. Zhou, and L. Yang, "The urban traffic under the influence of urban development intensity", Urban Planning Forum, vol. 2, no. 49, pp. 75-80, 2005.

[10] UN, "National Account Statistics", New York: Martin's Press, 1986-1996.

[11] The World Bank. World Development Report, Washington, D.C: United Nations Publication, 1986-1996.

Received: May 26, 2015

Revised: July 14, 2015

Accepted: August 10, 2015

(C) Wang et al.; Licensee Bentham Open.

This is an open access article licensed under the terms of the (https://creativecommons.org/licenses/by/4.0/legalcode), which permits unrestricted, noncommercial use, distribution and reproduction in any medium, provided the work is properly cited. 